\title{
Imagens técnicas: origem e implicações segundo Vilém Flusser
}

\author{
Technical images: origins and implications according to Vilém Flusser \\ Douglas João Orben ${ }^{1}$ \\ (douglasorben@hotmail.com) \\ http://dx.doi.org/10.5216/cei.v16i1.25724
}

\section{Resumo}

$\mathrm{O}$ artigo analisa, inicialmente, a apresentação flusseriana do desenvolvimento das estruturas humanas de expressão e significação da realidade. Tal processo tem seu início na pré-história, a qual é superada pelo pensar histórico que, por fim, produz as condições abstrativas para o surgimento da pós-história. A segunda parte do texto contempla as implicações causadas pela programação das imagens técnicas na sociedade pós-histórica, na medida em que o significado do mundo encontra-se determinado pelas tecno-imagens.

Palavras-chave: Flusser. Imagem. Pós-história.

\begin{abstract}
This article analyzes, initially, the Flusserian presentation of the development of human structures of expression and signification of reality. Such process has its inception in prehistory, which is overcome by the historical thinking that, therefore, produces the abstractive conditions for the post-history arising. The second part of the text contemplates the implications caused by technical images programming in the post-historic society, once the world's meaning finds itself determined by techno-images.
\end{abstract}

Keywords: Flusser. Image. Post-history

\section{Introdução}

$\mathrm{A}$ máquina fotográfica, que se comparada com muitos outros aparelhos existentes poderia até ser considerada simples e de pouca importância, para Vilém Flusser é o modelo a partir do qual a sociedade contemporânea deve ser analisada. Apesar de sua simplicidade e fácil manuseio, a máquina fotográfica é, para a grande maioria de seus operadores, desconhecida em suas virtualidades e programações. Ela é caixa preta, para o fotógrafo. Neste universo, o homem torna-se um funcionário que maneja os aparelhos, mas desconhece seu funcionamento. Esta é, pois, a grande questão que os aparelhos técnicos nos impõem: como compreender aquilo que foge à sua mera materialidade, como esclarecer as suas virtualidades programadas.

\footnotetext{
${ }^{1}$ Mestrando do Programa de Pós-graduação em Filosofia da Pontifícia Universidade Católica do Rio Grande do Sul - PUCRS e professor do curso de Filosofia da Faculdade Palotina FAPAS (Santa Maria).
}

Comun \& Inf, v. 16, n. 1, p. 113-126, jan./jun. 2013 
Flusser denomina o universo das imagens técnicas de "pós-histórico", pois ele é a síntese entre uma pré-história dominada por imagens pictóricas e o universo histórico, o qual se inicia com a escrita linear e culmina com os mais abstratos textos científicos. Neste processo, o mundo ganha significado de acordo com o período de seu desenvolvimento: para o homem pré-histórico o significado da realidade era expresso e determinado pelas imagens tradicionais, por meio de pinturas e figuras pictóricas; com o surgimento da escrita, o sentido da realidade passa a ser definido pelos conceitos, o homem torna-se um ser letrado e a sociedade organiza-se a partir de tratados, teses e textos científicos; a pós-história, por sua vez, é caracterizada pelo surgimento dos aparelhos produtores de imagens técnicas. Em tal domínio, a sociedade encontra-se orientada pelas imagens técnicas, pois são estas que determinam o sentido do mundo pós-histórico.

\section{Pré-história}

Para Flusser, as imagens são o esboço da tentativa humana de representar algo. Elas são a manifestação da capacidade imaginativa de criar figuras iconográficas, as quais pretendem representar o mundo. Pela capacidade de abstração das dimensões fenomênicas do mundo, as imagens são produzidas mediante o engenho criativo da imaginação que permite reconstruir as dimensões abstraídas, criando assim figuras abstratas. Segundo Flusser, “as imagens são, portanto, resultado do esforço de abstrair duas das quatro dimensões de espaço-tempo, para que se conservem apenas as dimensões do plano.” (FLUSSER, 2002, p. 7). Esta concepção corresponde ao que Flusser vai denominar de imagens tradicionais, em oposição a um segundo tipo de imagem, as imagens técnicas.

As imagens tradicionais representam o modo de expressão do mundo pré-histórico, onde a escrita ainda não existia e a representação se dava por imagens pictóricas, produzidas mediante capacidade imaginativa e expressas em desenhos, pinturas e figuras planas. No universo pré-histórico a faculdade operante é, sobretudo, a imaginação. É, pois, ela que possibilita a abstração e a codificação das imagens (condição para a produção das imagens), bem como a descodificação que implica na capacidade de compreensão das representações imagéticas. No processo de decodificação das imagens, o observador vagueia pela superfície plana da mesma, o olhar não segue uma temporalidade linear, mas sim uma articulação circular. Tal capacidade imaginativa de decodificar imagens, Flusser vai denominar de scanning. Neste sentido, “o traçado do scanning segue a estrutura da imagem, mas também os impulsos no íntimo do observador. O significado decifrado por este método será, pois, 


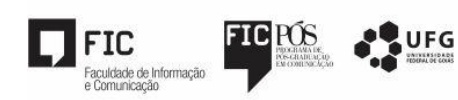

resultado da síntese entre duas "intencionalidades": a do emissor e a do receptor" (FLUSSER, 2002, p. 7-8).

A temporalidade do mundo pré-histórico acompanha o ritmo do scanning, pois o seu (do mundo) significado se apresenta em tal processo de decodificação de imagens. Este não é o tempo linear da história, mas o tempo circular, o tempo do eterno retorno que dá significado ao mundo préhistórico. Na decodificação da temporalidade imagética, "o vaguear do olhar é circular: tende a voltar para contemplar elementos já vistos. Assim, o "antes" se torna “depois", e o "depois" se torna "antes". O tempo projetado pelo olhar sobre a imagem é o eterno retorno.” (FLUSSER, 2002, p. 8). O mundo das imagens tradicionais é determinado pelo retorno, pela lei do destino que atribui significado às figuras num processo circular. Nesta dinâmica, as imagens são decodificadas, passando assim a atribuir significado à realidade.

No mundo das imagens tradicionais as relações não são determinadas por uma lei causal (causaefeito), pois o tempo não segue uma ordem linear. Segundo Flusser, o universo pré-histórico é regido pelo tempo mágico, orientado pela imaginação que produz significado relacional, reversível e circular. Como o próprio autor expressa:

\begin{abstract}
O tempo que circula e estabelece relações significativas é muito específico: tempo de magia. Tempo diferente do linear, o qual estabelece relações causais entre eventos. No tempo linear, o nascer do sol é a causa do cantar do galo; no circular, o cantar do galo dá significado ao nascer do sol, e este dá significado ao cantar do galo. Em outros termos: no tempo da magia, um elemento explica o outro, e este explica o primeiro. O significado das imagens é o contexto mágico das relações reversíveis (FLUSSER, 2002, p. 8).
\end{abstract}

O mundo pré-histórico, significado pelas imagens tradicionais, entra em crise na medida em que as imagens deixam de representar a realidade, interpondo-se entre o mundo e o homem como tapumes. Neste contexto, as imagens não mais orientam o significado do mundo, como mapas, mas acabam criando biombos que bloqueiam o acesso ao mundo. Como biombo, a imagem torna-se vazia, pois nada mais representa e, assim, não mais necessita ser decodificada. Se a imagem não mais representa o mundo, se ao invés de representá-lo ela passa a escondê-lo, então o significado iconográfico torna-se uma idolatria $^{2}$, passa-se a viver em função das imagens. Tal é, pois, o panorama da crise das imagens tradicionais:

\footnotetext{
2 Idolatria, para Flusser: "incapacidade de decifrar os significados da ideia, não obstante a capacidade de lê-la, portanto, adoração da imagem” (FLUSSER, 2002, p. 77-78).
}

Comun \& Inf, v. 16, n. 1, p. 113-126, jan./jun. 2013 
Imagens têm o propósito de representar o mundo. Mas, ao fazê-lo, interpõem-se entre mundo e homem. Seu propósito é serem mapas do mundo, mas passam a ser biombos. O homem, ao invés de se servir das imagens em função do mundo, passa a viver em função das imagens. Não mais decifra as cenas de imagem como significados do mundo, mas o próprio mundo vai sendo vivenciado como conjunto de cenas. Tal inversão da função das imagens é idolatria. Para o idólatra - o homem que vive magicamente - a realidade reflete imagens (FLUSSER, 2002, p. 9).

Na medida em que as imagens tradicionais deixam de representar algo, ao tornarem-se biombos que escondem a realidade, surge um novo modo de significar o mundo, a saber: o conceitual. A escrita conceitual nasce do esgotamento das imagens tradicionais, na tentativa de acabar com a idolatria pictórica e redefinir o significado da realidade a partir do conceito. Surge assim o pensar histórico.

\section{História}

A invenção da escrita ${ }^{3}$ supera as imagens tradicionais e inaugura o período histórico. A escrita conceitual está um passo além do plano imagético, pois a mesma abstrai três das quatro dimensões da realidade, restando apenas o símbolo conceitual. Assim, o texto (a escrita linear) exige uma capacidade imaginativa ainda maior, uma vez que o nível de abstração é mais elevado do que o da imagem tradicional. No mesmo sentido, a decodificação dos textos também é mais complexa, já que a sua compreensão envolve uma maior capacidade abstrativa. Para Flusser, "a escrita funda-se sobre a nova capacidade de codificar planos em retas e abstrair todas as dimensões, com exceção de uma: a da conceituação, que permite codificar textos e decifrá-los. Isso mostra que o pensamento conceitual é mais abstrato que o pensamento imaginativo, pois preserva apenas uma das dimensões do espaçotempo" (Flusser, 2002, p. 10). Com o surgimento da escrita, o homem (re)significou a realidade, porém se afastou dela ainda mais. $\mathrm{O}$ texto não significa diretamente a realidade, senão que teorias, ideias e conceitos sobre o real. Ele surge da necessidade (como uma tentativa) de explicar as imagens tradicionais, as quais haviam perdido sua capacidade significativa.

Ao apresentar uma explicação para as imagens tradicionais que se encontravam esgotadas em seu significado, o texto introduz uma nova concepção de temporalidade: não mais cíclica, senão que

\footnotetext{
${ }^{3}$ Neste sentido, Flusser, na obra $O$ Universo das Imagens Técnicas, esclarece: "Dezena de milênios se passaram até que tivéssemos aprendido a tornar transparente as imagens, a "explicá-las", a arrancar com os dedos os elementos da superfície das imagens e a alinhá-los a fim de contá-los; até que tivéssemos aprendido a rasgar o tecido contexto imaginado e a enfiar os elementos sobre linhas, a tornar as cenas "contáveis" (nos dois sentidos do termo), a desenrolar e desenvolver as cenas em processos, vale dizer, a escrever textos e a "conceber o imaginado". Consequentemente, a conceituação é o terceiro gesto abstraidor (abstrair a largura da superfície); graças a ele o homem transforma a si próprio em homem histórico, em ator que concebe o imaginado.” (FLUSSER, 2008, p. 17-18).
} 
linear e contínua ordenada de acordo com a relação de causalidade. O texto só ganha significado na medida em que seus símbolos são ordenados e lidos dentro da sequência linear, a qual segue as regras de uma gramática, fundamentada na estrutura causal da lógica formal.

Com a difusão da escrita, sobretudo a partir da invenção da imprensa, a temporalidade torna-se essencialmente linear e progressiva; surge assim a consciência histórica. O texto deve ter começo, meio e fim. A sociedade torna-se letrada, os textos tornam-se predominantes, acessíveis aos mais diversos públicos. Com efeito, o significado mágico das imagens tradicionais é eliminado pela racionalidade conceitual. A razão histórica desencanta o mundo imagético, exorciza a idolatria e afirma a lógica da causalidade mecânica, calculada e em contínuo progresso histórico. Tem-se, portanto, a soberania do conceito em detrimento da imagem: a superação da racionalidade abstrata e a negação da imaginação ${ }^{4}$.

Contudo, ao negar as imagens, os textos perdem seu poder imaginativo. Eles se tornam inimagináveis, não mais decifráveis. O discurso textual abstrai-se a tal ponto das imagens tradicionais que os conceitos deixam de ser significativos, eles perdem seu poder de explicar o mundo. Neste sentido, os textos que deveriam mediar a relação entre o homem e as imagens, "podem tapar as imagens que pretendem representar algo para o homem. Ele passa a ser incapaz de decifrar textos, não conseguindo reconstituir as imagens abstraídas. Passa a viver não mais para se servir dos textos, mas em função destes" (Flusser, 2002, p. 11). Surge assim a textolatria ${ }^{5}$, na medida em que os textos tornam-se tão abstratos, formais e lógicos que nada mais significam (não obstante a capacidade de lêlos), são intocáveis: sem qualquer contato com o mundo real.

No apogeu do período histórico, o texto distanciou-se do concreto e com isso deixou de ser mediação e tornou-se biombo, ele não mais representa imagens, pois perdeu seu poder explicativo. Para Flusser, "o propósito de toda abstração é o de tomar distância do concreto para poder agarrá-lo melhor" (Flusser, 2008, p. 20). É por esta razão que os textos se tornam biombos, escondem por vezes a realidade que pretendem explicar: "abstrair não é progredir, mas regredir, é um reculer pour mieux sauter. De maneira que a história da cultura não é a série de progressos, mas dança em torno do concreto. No decorrer de tal dança torna-se sempre mais difícil, paradoxalmente, o retorno para o concreto" (FLUSSER, 2008, p. 20).

\footnotetext{
${ }^{4}$ A negação da imaginação e a afirmação de uma racionalidade mecânico e calculista é visível, por exemplo, no período da Revolução Científica do século XVII e XVIII.

5 Para Flusser, textolatria: "incapacidade de decifrar conceitos nos signos de um texto, não obstante a capacidade de lê-los, portanto, adoração ao texto” (FLUSSER, 2002, p. 79).
}

Comun \& Inf, v. 16, n. 1, p. 113-126, jan./jun. 2013 


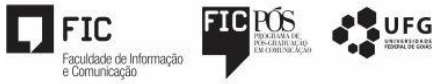

Neste contexto de crise da escrita, perante a dominante incompreensão de textos cada vez mais abstratos, surge um novo vetor de significado, a saber: as imagens técnicas. Estas são, por assim dizer, a síntese entre as imagens tradicionais e o texto: preservam a dimensão imagética, mas, não obstante, são produtos de textos científicos. Neste sentido, as imagens técnicas são invenções criadas por textos abstratos. Na medida em que a linguagem (expressa em textos) científica separa-se da realidade, abstrai as ambiguidades e as tensões do real e cria uma linguagem artificial (simbólica e lógica), ela assim produz os códigos e programas que vão gerar as imagens técnicas.

Quanto mais o texto se torna linear mais se torna técnico, e mais se torna preciso. Essa tecnificação da linguagem busca retirar da mesma a ambiguidade da experiência do ser no mundo, e leva à linguagem científica, e mais tarde, à linguagem algorítmica, lógica, matemática. $\mathrm{O}$ código de um programa de computador e a linguagem algorítmica são exemplos

de precisão absoluta na descrição linear de uma experiência. (REVISTA DE COMPUTAÇÃO E TECNOLOGIA (ReCeT), 2010, p. 34).

Com o aparecimento das imagens técnicas, a soberania do texto é posta em xeque. Esta nova categoria de imagem vai aos poucos assumindo a posição de definidora de sentido, que antes era dominada pelos textos escritos. Tal processo, segundo Flusser, culmina num estágio por ele denominado de pós-histórico, no qual as imagens técnicas assumem a função de vetores de significado, antes operada pelos textos.

\section{Pós-história}

A crise dos textos tem como consequência o naufrágio da temporalidade histórica. Ao perder o seu poder explicativo, o conceito elimina igualmente o significado do progresso histórico, pois este é alimentado pela causalidade temporal, caracterizadora da escrita conceitual (linear). Com a derrocada da escrita, "lá, onde os textos não mais significam imagens, nada mais resta a explicar, e a história pára." (FLUSSER, 2002, p. 11). Neste contexto, a temporalidade histórica é superada, surgindo assim uma pós-história. Para Flusser, "pois é precisamente em tal mundo que vão sendo inventadas as imagens técnicas. E em primeiro lugar, as fotografias, a fim de ultrapassar a crise dos textos" (FLUSSER, 2002, p. 11).

As imagens técnicas nascem da tentativa de recuperar a capacidade imaginativa, negada pela textolatria. Elas são imagens que procuram suprir o esgotamento do texto e (re)significar a realidade, paralisada em conceitos inimagináveis. Mesmo opondo-se à textolatria, as imagens técnicas são 


\section{口些}

produzidas por aparelhos que, por sua vez, são a manifestação técnica de textos científicos. Nesta dialética, as imagens técnicas são, ao mesmo tempo, a negação e a conservação dos textos. Segundo Flusser, "imagens técnicas são, portanto, produtos indiretos de textos - o que lhes confere posição histórica e ontológica diferente das imagens tradicionais" (FLUSSER, 2002, p. 13).

Enquanto que as imagens tradicionais são pré-históricas, pré-alfabéticas, as imagens técnicas, por sua vez, são o produto de textos científicos, digitalmente codificados. Ora, sendo elas o efeito do mais alto grau de abstração textual, as imagens técnicas (mesmo sendo simples imagens) superam a abstração de primeiro grau (abstrair duas das dimensões da realidade) das imagens tradicionais. Portanto, "a imagem técnica é abstração de terceiro grau: abstrai uma das dimensões da imagem tradicional para resultar em textos (abstração de segundo grau); depois, reconstitui a dimensão abstraída, a fim de resultar novamente em imagem" (FLUSSER, 2002, p. 13).

Situadas no âmbito pós-histórico, a principal característica que diferencia as imagens tradicionais das imagens técnicas é a programação do aparelho produtor de imagens, presente nas últimas e não nas primeiras. No caso das imagens tradicionais, o significado é construído por meio de um ser humano, o qual busca representar iconograficamente a realidade fenomênica. Por outro lado, nas imagens técnicas, a representação se dá através de um aparelho científico (a máquina), previamente programado de acordo com determinados padrões. Não obstante o objetivo de ilustrar conceitos, as imagens técnicas são conceitos transformados em cenas. Elas pretendem reimaginar o mundo, negando assim a hegemonia do conceito, mas sem deixar de ser a expressão dos mesmos conceitos, implicitamente infiltrados na programação dos aparelhos produtores de imagens.

No mundo pós-histórico, as imagens técnicas passaram a predominar sobre os textos. São elas, pois, que determinam o significado do mundo, bem como o próprio sentido da realidade social. Para Flusser, entretanto, a predominância das imagens técnicas, na sociedade pós-histórica, deve ser analisada tendo em vista, sobretudo, a citada programação das mesmas. Pois, se consideradas como o produto de teorias e textos científicos, fica então claro que as mesmas não são janelas que permitem contemplar o mundo (como representações fieis e desinteressadas), mas sim conceitos (programados) transformados em imagens, as quais têm por objetivo projetar determinado sentido à realidade.

\section{Imagens técnicas: o domínio da programação}


Segundo Flusser, o mundo pós-histórico é caracterizado pela onipresença das imagens técnicas, principalmente a fotografia; "fotografias são onipresentes: coladas em álbuns, reproduzidas em jornais, expostas em vitrines, paredes de escritórios, afixadas contra muros sob forma de cartazes, impressas em livros, latas de conservas, camisetas" (FLUSSER, 2002, p. 37). Em tal sociedade, o significado das coisas encontra-se estreitamente relacionado com as imagens técnicas. No universo pós-histórico, o conceito encontra-se submetido à imagem: o texto é lido em função da imagem, a qual determina previamente, numa cena, todo o sentido do mesmo. Mais importante que o artigo escrito (livro, jornais, revistas, reportagem) é a capa (imagem) que ilustra tal artigo. No domínio das tecno-imagens, "o artigo é lido em função da fotografia, como que através dele. Não é o artigo que "explica" a fotografia, mas é a fotografia que "ilustra" o artigo" (FLUSSER, 2002, p. 55).

O homem pós-histórico está farto de textos, ele não tem mais o tempo necessário para adentrar (passo a passo, seguindo a ordem textual de começo, meio e fim, de acordo com a ideia de progresso linear da história) às demoradas explicações dos enfadonhos textos. A sociedade encontra-se, novamente, fascinada, encantada pelo poder mágico das imagens, agora tecnicamente produzidas. $\mathrm{O}$ homem, "ao ler o artigo, está sob a influência do fascínio mágico da fotografia. Não quer explicação sobre o que viu, apenas confirmação. [...] Explicações nada adiantam se comparadas com o que se vê. Não quer saber sobre causas ou efeitos da cena, porque é esta e não o artigo que transmite realidade" (FLUSSER, 2002, p. 57). Em tal sociedade, a magia das imagens técnicas determina o significado das coisas: "mostra o que é 'bom' e o que é 'mau'" (FLUSSER, 2002, p. 56), o que se deve e o que não se deve fazer, define o que é belo e o que é feio, como agir, ser e pensar.

E assim a fotografia vai modelando seus receptores. Estes reconhecem nela forças ocultas inefáveis, vivenciam concretamente o efeito de tais forças e agem ritualmente para propiciar tais forças. Exemplo: em fotografia de cartaz mostrando escova de dentes, o receptor reconhece o poder da cárie. Sabe que é força nefasta e compra a fim de passá-la ritualmente sobre os dentes, conjurando o perigo (espécie de sacrifício ao "deus Cárie”, ao Destino). (FLUSSER, 2002, p. 58).

Contudo, o que faz com que as imagens técnicas possuam tal poder mágico? O que determina este poder, já que a sua magia não é da mesma ordem das imagens tradicionais? Segundo Flusser, a resposta a estas questões depende da análise do conceito de "programa", pois na programação dos aparelhos encontra-se um modelo conceitual que será expresso em cenas, por meio de imagens técnicas. O que está por detrás de toda tecno-imagem é um programa, o qual foi gerado por textos 


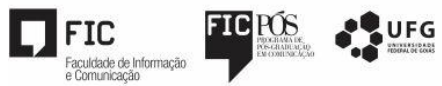

científicos (conceitos e modelos históricos, portanto). Deste modo, "as fotografias são imagens de conceitos, são conceitos transcodificados em cenas" (FLUSSER, 2002, p. 32). O conceito produz e define o programa, este, por sua vez, vai possibilitar e condicionar todas as imagens por ele produzidas. Assim, as imagens técnicas são a expressão de uma programação, presente no aparelho, a qual está determinada por modelos e padrões conceituais.

Todo aparelho produtor de imagens possui determinadas programações, são elas as virtualidades que condicionam e possibilitam seu funcionamento. Para Flusser, "se considerarmos o aparelho fotográfico sob tal prisma, constataremos que o estar programado é o que o caracteriza" (Flusser, 2002, p. 22), pois é o programa que possibilita (e ao mesmo tempo limita) toda e qualquer fotografia. O valor e a qualidade (possibilidades permitidas) do aparelho não estão em suas "partes duras" (hardware), senão que depende da qualidade de seu software, de suas virtualidades programadas. O software do aparelho pré-determina as possibilidades do mesmo. Ele programa os padrões e modelos a partir dos quais as imagens serão geradas. Neste caso, "as superfícies simbólicas que produz estão, de alguma forma, inscritas previamente ("programadas", "pré-escritas") por aqueles que o produziram" (FLUSSER, 2002, p. 22). Este sistema complexo de virtualidades que compõe o aparelho técnico, por vezes, é desconhecido pelos seus operadores. Para os funcionários que operam os aparelhos, tal dimensão é caixa preta: ela permanece assim quase totalmente desconhecida para a maioria deles, a despeito de seu bom funcionamento.

Considerando que a programação do aparelho já define previamente, a partir de determinados conceitos, as imagens produzidas, então as escolhas possíveis sempre estarão já determinadas. A liberdade expressa nas imagens técnicas, por mais astuciosas e inovadoras que elas possam ser, sempre vai ser apenas uma liberdade de escolha, nunca uma verdadeira liberdade. Sua escolha não é livre, mas sim uma escolha programada. A fotografia não consegue tanger o grau de liberdade expresso em algumas pinturas tradicionais, feitas por seres humanos, com tintas e pincel. As fotografias, num certo sentido, são sempre repetitivas e programadas ${ }^{6}$.

O fotógrafo "escolhe", dentre as categorias disponíveis, as que lhe parecem mais convenientes. Neste sentido, o aparelho funciona em função da intenção do fotógrafo. Mas sua "escolha" é limitada pelo número de categorias inscritas no aparelho: escolha programada. O fotógrafo não

\footnotetext{
${ }^{6}$ Segundo Flusser, esta afirmação não pode ser apressadamente generalizada, pois nem todas as fotografias são repetitivas e programadas, existem alguns poucos fotógrafos que, mesmo servindo-se de aparelhos programados, conseguem superar a programação e criar assim imagens originais.
}

Comun \& Inf, v. 16, n. 1, p. 113-126, jan./jun. 2013 
pode inventar novas categorias, a não ser que deixe de fotografar e passe a funcionar na fábrica que programa aparelhos. Neste sentido, a própria escolha do fotógrafo funciona em função do programa do aparelho (FLUSSER, 2002, p. 31).

A imagem, portanto, dependerá do programa escolhido. Este, por sua vez, foi produzido por determinados conceitos, pelo que a imagem encontra-se determinada indiretamente por conceitos. As imagens técnicas que dominam a sociedade pós-histórica, dentro desta lógica, são manifestações iconográficas de conceitos, modelos e padrões pré-definidos pelos programas. Sendo, destarte, produzidas a partir de virtualidades programadas, as imagens técnicas vão expressar significados programados. Na sociedade pós-histórica, o modo como as imagens técnicas determinam o significado das coisas segue a lógica (binária) cartesiana de conceitos claros e distintos: "eis como se produz o universo fotográfico: homens constroem aparelhos segundo o modelos cartesianos; em seguida, os alimentam com conceitos claros e distintos" (FLUSSER, 2002, p. 64). Neste caso, o conceito fundamental de "programação" não passa de um jogo de permutação ente elementos claros e distintos (FLUSSER, 2002, p. 64).

Com a onipresença das imagens técnicas na sociedade pós-histórica, quase nada escapa ao seu jogo de programação. Na concepção flusseriana, todas as cenas e lances seguem as regras de um jogo programado. Trata-se de programar o acaso: por mais que cada lance (imagem) não manifeste explicitamente a sua programação, muito embora cada imagem individual não seja a causa (suficiente) da programação absoluta dos sujeitos (como no caso da idolatria das imagens tradicionais, onde cada imagem possuía por si própria o poder de encantar os sujeitos), a despeito disso, numa série prolongada e repetitiva de lances (imagens), numa sociedade dominada por imagens técnicas, apresentadas à exaustão, a totalidade dos lances é inevitavelmente alienada no jogo da programação. Em outras palavras, embora a programação não seja (por vezes) evidente em cada imagem, pois elas (as imagens) se apresentam individualmente de forma aparentemente inofensivas e desinteressadas (parecem estar dispostas ao acaso), não obstante, observadas em sua totalidade e onipresença, o aparente acaso converte-se em necessidade: em sua totalidade a programação é plenamente efetivada. No jogo que engloba todas as imagens técnicas, portanto, a programação acontece necessariamente. Quanto mais 


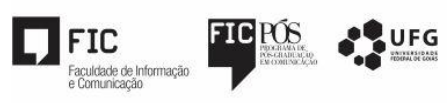

vasta for a série de lances, mais a programação vai sendo confirmada, elevando-se da aparente liberdade para a necessidade total ${ }^{7}$. Neste sentido, Flusser esclarece:

Todas as virtualidades inscritas no programa, embora se realizem ao acaso, acabarão se realizando necessariamente. Se guerra atômica estiver inscrita em determinados programas de determinados aparelhos, será realidade, necessariamente, embora aconteça por acaso. É neste sentido sumamente cretino que os aparelhos são oniscientes e onipotentes em seus universos (FLUSSER, 2002, p. 65).

A confirmação e a efetivação do programado é diretamente proporcional à produção e à difusão das imagens técnicas, já que (de forma implícita) cada uma delas é condição para a efetivação da programação, muito embora isso não seja visível em cada lance apresentado em cenas. A programação que se inicia aparentemente por acaso, termina com um condicionamento necessário, efetivando assim o que já estava escrito nas virtualidades do programa. Num último estágio, por assim dizer, "tais imagens programam magicamente a sociedade para um comportamento em função do jogo dos aparelhos" (FLUSSER, 2002, p. 65). A sociedade encontra-se encantada pelas imagens, acredita cegamente (como única alternativa) em seus conceitos, não mais questiona a programação.

Nesta situação, quem acredita que o significado das imagens técnicas revela-se em sua função, à semelhança das imagens tradicionais, de representar o mundo existente, como refletores da realidade; quem assim encara o universo imagético, está completamente enganado. Segundo Flusser, "os aparelhos não são refletores, mas projetores. Não "explicam” o mundo, como fazem as imagens tradicionais, mas “informam” o mundo” (FLUSSER, 2008, p. 71). Neste sentido, Flusser complementa: “o importante é que as imagens técnicas são projeções que projetam significado de dentro para fora, e que é precisamente isto o seu "sentido" (sinn, meaning)" (FLUSSER, 2008, p. 69).

Os conceitos e padrões difundidos pelas imagens técnicas, através das mais diversas formas midiáticas, efetivam a programação da sociedade. Eles determinam modelos, os quais são difundidos pelas imagens que (na lógica da programação) condicionam as escolhas possíveis de acordo com os modelos programados. O que parece ser um ato livre, portanto, já está previamente determinado, tornando-se assim uma escolha programada (escolhe dentro de um padrão definido). Na sociedade programada, “o pretenso significado das imagens técnicas não passa de imperativos a ser obedecidos.

\footnotetext{
${ }^{7}$ Para exemplificar tal programação inevitável, Flusser cita um caso simples de programação, que é gradativamente confirmada, a saber: a do jogo de dados. Segundo o autor, "tal jogo obedece ao acaso, que por sua vez vai se tornar necessidade. Exemplo extremamente simples de programa é um jogo de dados: permuta os elementos " 1 " e " 6 " ao acaso. Todo lance individual é imprevisível. Mas a longo prazo, o "1" será realizado em cada sexto lance. Necessariamente" (FLUSSER, 2002, p. 65).
} 


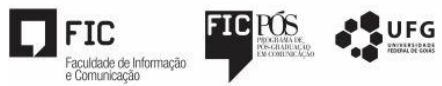

Tal imperativo, tal ponta de dedo que aponta o caminho a ser seguido, é "o que as imagens técnicas significam"' (FLUSSER, 2008, p. 73). Funcionando como imperativos, os conceitos, infiltrados em imagens técnicas, apontam o sentido e determinam (de forma a priori) o futuro da sociedade. Retornase assim ao tempo determinado pelas figuras do destino, as quais condicionam a existência humana de acordo com um programa pré-estabelecido.

Por fim, no diagnóstico flusseriano, a sociedade segue cegamente os padrões estampados nas imagens técnicas: "vivenciamos, conhecemos, valoramos e agimos cegamente em função delas" (FLUSSER, 2008, p. 73). Tal programação social persistirá, "a menos que decifremos o que tais imperativos, tais dedos imperativos estendidos significam; a menos que descubramos os seus programas" (FLUSSER, 2008, p. 73). Contudo, tal análise não será aqui desenvolvida, ficando apenas como um aceno da saída de tal caverna mágica, astuciosamente arquitetada atualmente pelas imagens técnicas.

\section{Considerações finais}

$\mathrm{Na}$ medida em que o contexto pós-histórico é dominado pelos aparelhos programados, as imagens técnicas ganham vigor e abrangência a tal ponto de eliminarem a postura crítica. Elas se convertem em figuras divinas, são onipresentes, oniscientes e onipotentes, pois o sentido por elas indicado não é mais questionado. Segundo Flusser, no domínio das imagens técnicas, as praças públicas e as catedrais são substituídas pelos shoppings, são eles os centros de programação da sociedade contemporânea. Este é o espaço onde a superficialidade das imagens técnicas predomina, onde os modelos são lançados e daí apontam o sentido a partir do qual os homens passam a viver.

A superficialidade das imagens técnicas produz, portanto, uma sociedade igualmente superficial, tão vazia, solitária e sem sentido quanto os pontos (pixel) isolados que articulam uma figura, sobre um plano vazio que está por detrás de todas as imagens técnicas. Para cobrir este vazio, as imagens apresentam modelos que ilusoriamente preenchem o nada com figuras. Todavia, em todas as imagens técnicas o vazio continua lá, a superficialidade dos pontos é apenas uma ilusão: a sua manutenção depende da superficialidade do observado, ela somente se sustenta a uma determinada distância. Quando observadas bem de perto, as imagens técnicas perdem o sentido, o vazio que elas escondem então se revela. $\mathrm{O}$ absurdo, contudo, evidencia-se na medida em que a materialidade do mundo passa a ser significada, a ganhar sentido, através de tal imaterialidade e vagueza das imagens técnicas.

Comun \& Inf, v. 16, n. 1, p. 113-126, jan./jun. 2013 
Artigo submetido em 05/08/2013 e aceito em 27/08/2013.

\section{Referências}

DUARTE, Rodrigo. A plausibilidade da pós-história no sentido estético. Trans/Form/Ação, Marília, v.34, 2011. Disponível em: <http://www.scielo.br/scielo.php?pid=S0101-31732011000400010\&script= sci arttext $>$. Acesso em: 21 maio 2013.

FINGER, Anke. Vilém Flusser: an intodution. Minneapolis (MN): Univ. of Minnesota, 2011. 176p.

FLUSSER, Vilém. A dúvida. Rio de Janeiro: Relume-Dumará, 1999.

FLUSSER, Vilém. A história do Diabo. São Paulo: Anablume, 2005.

FLUSSER, Vilém. Da religiosidade: a literatura e o senso de realidade. São Paulo: Escrituras, 2002. FLUSSER, Vilém. Fenomenologia do brasileiro: em busca do novo homem. Introdução de Gustavo Bernardo Krause. Rio de Janeiro: Uerj, 1998.

FLUSSER, Vilém. Ficções filosóficas. São Paulo: EDUSP, 1998.

FLUSSER, Vilém. Filosofia da caixa preta. São Paulo: Relume Dumará, 2002.

FLUSSER, Vilém. Língua e realidade. São Paulo: Annablume, 2004.

FLUSSER, Vilém. O universo das imagens técnicas: elogio da superficialidade. São Paulo: Annablume, 2008. 206p.

FLUSSER, Vilém. Pós-história: vinte instantâneos e um modo de usar. São Paulo: Duas cidades, 1983.

OLIVEIRA COSTA, Rachel C. Imagem e linguagem na pós-história de Vilém Flusser. 2009. Dissertação de mestrado - Universidade Federal de Minas Gerais, Faculdade de Filosofia e Ciências Humanas. 2009. Disponível em: <http://www.bibliotecadigital.ufmg.br/dspace/bitstream/handle/1843 IARBZ7TSH92/;jsessionid=C0AC52BAF96AEA7D338C8120949B1D2C?sequence=1 >. Acesso em: 21 maio 2013.

PIACENTINI. Maurício T. O jogo eletrônico como sequência de imagens técnicas e o impacto cognitivo do acesso ao código. Revista de Computação e Tecnologia (ReCeT), São Paulo, v. 2, n. 1, p. 34, 2010. Disponível em: 〈http://revistas.pucsp.br/ReCET>. Acesso em: 21 maio 2013.

Comun \& Inf, v. 16, n. 1, p. 113-126, jan./jun. 2013 